\title{
А.В. Верещагина
}

Владивостокский государственный университет экономики и сервиса

Владивосток. Россия

\section{Идея неприкосновенности личности и опыт её реализации в досоветской России}

Современное понимание идеи неприкосновенности личности в России начинает формироваться с XVIII в.
В статье Аана периодизация развития и практической реализации идеи неприкосновенности личности.
Автор Ааёт характеристику законопроекта конституционных Аемократов, внесённого в I Государствен-
ную Ауму; излагает причины неудач дореволюционного российского парламента по легитимации этого
закона. В публикации особое внимание уделено Временному положению о милиции 1917 г., в котором
впервые в России была создана нормативная модель института судебного контроля за Аеятельностью
милиции по ограничению прав и свобоА мичности, включая её неприкосновенность.

Ключевые слова и словосочетания: досоветская Россия, история либеральной мысли, право, парламентаризм, Временное правительство, неприкосновенность личности, судебный контроль, Временные правила о милиции 1917 г.

\section{A.V. Vereshchagina}

Vladivostok State University of Economics and Service Vladivostok. Russia

\section{Personal immunity idea and the experience of its realization in pre-Soviet Russia}

\begin{abstract}
The modern personal immunity idea in Russia began to formalize since XVIII century. The development and practical realization of the personal immunity idea in Russia can be divided into three periods. The author characterizes the introduction of the draft law, elaborated by constitutional democrats, in the First State Duma and expounds causes which did not allowed to adopt it. In the publication the special attention was paid to the Temporary rules about militia of 1917. In this act firstly in Russia was created the normative model of the judicial control institute for the militia activity on the restriction of the rights of citizens, including its immunity.

Keywords: pre-Soviet Russia, history of liberal ideology, law, State Duma, Temporary Government, personal immunity, judicial control, Temporary rules about militia of 1917 .
\end{abstract}

В развитии идеи личности в дореволюционной России можно выделить три периода по критерию практического воплощения: I - с начала XVIII в. до середины XIX в.; II - с середины XIX в. до февраля 1917 г.; III - февраль - октябрь 1917 г.

C начала XVIII в. начинается оформление идеи неприкосновенности личности, приближенной к её современному пониманию. Этот процесс проходит в рамках зарождения и развития в России либеральной идеологии [6, с. 35-36; 13, с. 30]. Спорной среди исследователей является только датировка появления этого феномена.

Верещагина Алла Васильевна - канд. юрид. наук, доцент, заведующая кафедрой уголовно-правовых дисциплин Института права; e-mail: vereschagina_alla@mail.ru.

Vereshchagina A.V. - candidate of legal sciences, associate professor, Head of the Department of Criminal Law disciplines. 
А.В. Верещагина. ИАея неприкосновенности мичности и опыт её реализации в Аосоветской России

Некоторые авторы (Л.А. Дербов, И.З. Серман) увязывают начало просвещения с деятельностью Кантемира и М.В. Ломоносова, некоторые (Г.П. Макогоненко) указывают 20-е годы XVIII в., когда усиливается взаимопроникновение культур $[4$, c. 76]. Именно в это время появляется труд И.Т. Посошкова «Книга о скудости и богатстве», автор которого описывает российское общество и государство и высказывает идеи, позволяющие изменить Россию к лучшему.

Это сочинение примечательно многими моментами, мы отметим лишь некоторые: понимание неразрывной связи состояния экономики и правосудия; первое целостное описание российского правосудия и особая роль суда в обеспечении неприкосновенности личности [18, с. 54-59, 77, 80, 92].

Суждения И.Т. Посошкова, в том числе в части важности для процветания государства надлежащей юстиции, основной задачей которой является ограждение прав и свобод личности, включая её неприкосновенность, развиваются авторами второй половины XVIII в.

Например, Д.И. Фонвизин вторит характеристике суда, данной И.Т. Посошковым. При этом важной во взглядах Д.И. Фонвизина является подмеченная им обусловленность фактического использования предоставляемых личности прав её экономической состоятельностью [4, с. 81-82].

Подобные рассуждения мы находим, в частности, у первого профессора в области юриспруденции «из природных россиян» С.Е. Десницкого [8, с. 292-332], а в первой половине XIX в. у российских государственных деятелей (М.А. Балугьянский, Н.С. Мордвинов, М.М. Сперанский и др.), декабристов (П.С. Батеньков, Н.М. Муравьёв, П.И. Пестель, С.П. Трубецкой и др.), революционеров (А.И. Герцен, Н.П. Огарёв), публицистов (Н.А. Добролюбов, Н.Г. Чернышевский) и учёных (А.П. Куницын, ), описывавших неприглядные стороны российского правосудия и высказывавших идеи его усовершенствования, целью которых было обеспечение судебной защиты личности [4, с. 83-87, 117-123].

Первый опыт преломления теоретических рассуждений о важности неприкосновенности личности и возможности её ограничения только в строго оговоренных законом случаях в практическую плоскость (II период) связан с разработкой и принятием Судебных уставов 1864 г. Идея личности, по мнению И.Я. Фойницкого, то новое, что составляло их «наиболее характерную черту...» [13, с. 43].

Идея личности в Судебных уставах реализовывалась посредством признания равенства всех перед законом и судом, гласности и устности судоговорения, учреждения институтов суда присяжных и присяжной адвокатуры и т.д.

Однако важнейший для ограждения прав личности институт судебного контроля за досудебным производством, о необходимости которого писал еще И.Т. Посошков, фактически создан не был, хотя и презюмировался составителями Судебных уставов. Зачатки института судебного контроля в Уставах проявлялись в трёх констатациях: 1) предварительное следствие осуществляется представителем судебной власти судебным следователем, поэтому ограничение прав исходит от неё; 2) задержание должно производиться с соблюдением формальных условий, нарушение которых влечёт немедленное освобождение задержанного; 3) суд имеет 
право рассматривать жалобы на следственные действия [1, с. 44-46; 2, с. 160-168; 3, с. 79-81].

Наличие этих положений наметило, но не создало действенного механизма судебного контроля за соблюдением прав личности в досудебном производстве, поскольку 1) судебный следователь находился де-факто в подчинении прокурора, несмотря на свою судебную принадлежность; 2) в законе не прописывалась процедура осуществления судебного контроля за задержанием и 3) большинство российских подданных в силу своей малограмотности (безграмотности) и низких доходов не могли воспользоваться правом обжалования. Словом, конструкция судебного контроля за применением процессуального принуждения и по ограждению неприкосновенности личности оставляла желать лучшего.

Пореформенное законодательство, являвшееся следствием адаптации изначально достаточно либеральной нормативной модели юстиции к существовавшему в Российской империи социально-экономическому контексту, усилило присутствие исполнительных органов власти в судебной сфере и снижало защищённость вовлекавшихся в орбиту уголовного судопроизводства лиц. Следует также учитывать то обстоятельство, что значительные территории России были объявлены на положении чрезвычайной или усиленной охраны, т.е. там применялось чрезвычайное законодательство и Уставы не действовали, а на некоторых территориях вплоть до 1917 г. в полном объёме Уставы так и не были введены (в частности, в Приморской области (ныне Приморский край)).

События начала XX в. не только обострили социально-экономические проблемы, но и способствовали активизации разработки оптимальной модели взаимоотношений личности и государства. Вопреки различиям в методологических подходах исследователи были едины во мнении: есть сфера, в которую государство вторгаться может только в крайних, предусмотренных законом случаях. Такой сферой являются естественные права и свободы личности, к коим относится и личная неприкосновенность $[11$, с. 554,556$]$.

Понимание необходимости корректировки взаимоотношений личности и государства имелось и у правящей элиты. В Именном указе Правительствующему Сенату от 12 декабря 1904 г. Император изложил направления возможных реформ. Пункт 3 акта декларировал преобразование юстиции: «...в целях охранения равенства перед судом лиц всех состояний, внести должное единство в устройство судебной в Империи части и обеспечить судебным установлениям всех степеней необходимую самостоятельность» [14].

Указ фактически воспроизводил идеи судебной реформы Александра II и инициировал подготовку законопроектов о преобразовании местного суда, о неприкосновенности личности, об ответственности должностных лиц за преступления по службе, о допуске защиты на предварительное следствие.

В преддверии принятия Основных государственных законов Российской империи возглавлявший правительство граф С. Ю. Витте по собственному почину подготовил записку о необходимости политических реформ и 9 октября 1905 г. представил её Императору. 
А.В. Верещагина. ИАея неприкосновенности мичности и опыт её реализации в Аосоветской России

В этом документе С.Ю. Витте излагает сложившееся в теории понимание взаимоотношений личности и государства. Право, пишет С.Ю. Витте, создаётся для определения границ свободы, а государство создаётся во имя права. Причина «нестроения России» заключается в неумелых и непоследовательных действиях, неразборчивости средств, к которым прибегает администрация и которые дали роковой результат.

Свобода должна стать лозунгом правительства для спасения государства. Государственная власть должна перестроиться: устранить произвол и самовластие, основанные на исключительных законах; обеспечить свободу вероисповедания, слова, собраний и союзов, равноправие граждан и неприкосновенность личности. Делать это нужно искренне, не как уступки, а как цель деятельности правительства [9, с. 51-61].

Представляется, что накопленные теоретические знания, осознание необходимости преобразования взаимоотношений личности и государства, сформировавшееся не только у учёных, но и представителей других слоёв общества, на фоне обострившегося социально-экономического кризиса создали предпосылки решения проблемы неприкосновенности личности.

Такую попытку предприняли депутаты Первой Государственной Думы. В Проекте обращения депутатов к Императору в качестве «главной язвы» государственной жизни указывается «... самовластие чиновников, отделяющих Царя от народа» $[19$, с. 75$]$. Средством обновления России, как считали депутаты, могли быть только «... свобода, самодеятельность и участие самого народа в осуществлении власти законодательной и в контроле над властью исполнительной». Предпосылкой созидательной работы должно быть освобождение России от действия чрезвычайных законов об усиленной и чрезвычайной охране и военном положении, «под прикрытием которых особенно развилось и продолжает проявляться самовластие безответственных чиновников...» [19, с. 75]. Достижению цели обновления России будет способствовать принятие ряда законов, первым из которых в Проекте обращения значился закон о неприкосновенности личности [19, с. 75]. Основой предложенного в Проекте обращения плана законодательных работ стала правовая программа кадетов, что неслучайно, поскольку членами этой партии были лучшие юристы того времени: М.М. Винавер, С.А. Котляревский, В.Д. Кузьмин-Караваев, В.Д. Набоков, П.И. Новгородцев и др. [15, с. 10-11; 17, с. 60-66].

Именно представители фракции кадетов внесли законопроект «В обеспечение действительной неприкосновенности личности», с которого началась законодательная работа Первой Государственной Думы.

На заседании 8 мая 1906 г. приняли предложение 31 депутата о его подготовке. В Комиссию из 15 депутатов, которой поручили разработку проекта, вошли помимо упоминавшихся выше Л.М. Брамсон, П.А. Гейден, Н.А. Гредескул, М.М. Ковалевский, Ф.Ф. Кокошкин, А.Р. Ледницкий, Ф.И. Новодворский, М.Я. Острогорский, Л.И. Петражицкий и Н.И. Семёнов. В качестве основной цели, как пояснил представлявший законопроект П.И. Новгородцев, члены комиссии видели создание хартии вольностей из немногих и ясных положений, закреплявших 
права граждан и обязанности власти, которая бы стала основной правопорядка в России [16, с. 148].

Подготовленный документ (проект комиссии 15-ти) содержал следующие положения: наказание не иначе как по решению суда, гарантии прав личности при применении мер процессуального принуждения и производстве следственных действий - арестов, обысков, выемок, осмотров почтовой и телеграфной корреспонденции, мер административного принуждения в виде высылки, полицейского надзора, взысканий, ограничений в праве передвижения, исключительной подсудности. При их разработке члены комиссии основывались на лучших образцах зарубежного законодательства. Окончательный вариант проекта не обсуждался в I Государственной Думе. Однако он стал основой проекта межведомственной комиссии под руководством товарища Министра внутренних дел А.А. Макарова, которая занималась им в период «междудумья».

В Государственной Думе второго созыва работа над законопроектом возобновилась, чему способствовала предложенная П.А. Столыпиным программа реформ. Одним из подготовленных и представленных в Государственную Думу в рамках этой программы правительственных законопроектов являлся законопроект, направленный на обеспечение неприкосновенности личности.

Концепция проекта была созвучна проекту Комиссии 15-ти (І Государственная Дума) и сводилась к недопустимости применения личного задержания, проведения обыска, вскрытия корреспонденции без судебного решения, а также обязательности судебного контроля в течение суток за законностью и обоснованностью полицейского ареста. Ограничение этих прав допускалось по мысли разработчиков при введении по одному из двух оснований исключительного положения: в случае войны или народных волнений. Предлагалось упразднить административную высылку [7, с. 26-45].

Несмотря на симпатии к проекту комиссии 15-ти, во II Государственной Думе за основу взяли предложения комиссии А.А. Макарова, что позволяло избежать месячного срока получения правительственного заключения.

Подготовленный Комиссией из 33 депутатов II Государственной Думы законопроект (в неё входили В.М. Гессен, Н.С. Долгополов, Л.Г. Люц, П.И. Новгородцев и др.) немногим отличался от проекта комиссии 15-ти.

К отличиям охранительного свойства можно отнести более неопределённую формулировку исключительной подсудности; возложение обязанности на частных лиц доставить задержанное ими лицо в полицию, а не в суд, как это было в проекте комиссии 15-ти; предоставление судебным органам права заключать под стражу на две недели лицо, в отношении которого перед судом не возбуждено уголовное преследование; некоторое ограничение прав судей по надзору за законностью и обоснованностью задержания.

В целом законопроект, подготовленный комиссией II Государственной Думы, можно охарактеризовать как акт, который усилил «практичность» проекта, подготовленного комиссией 15-ти, в смысле приемлемости его для власти в связи с частичным отказом от идеи априорности законодательства о неприкосновенности личности. 
А.В. Верещагина. ИАея неприкосновенности мичности и опыт её реализации в Аосоветской России

В Государственную Думу третьего созыва правительство передало проекты, которые не рассмотрела Вторая Дума, в том числе законопроект о неприкосновенности личности.

4 декабря 1907 г. в III Государственной Думе избрали комиссию о неприкосновенности личности для работы над правительственным проектом, которую возглавил Я.Г. Гололобов, а докладчиком стал Г.Г. Замысловский, придерживавшийся крайне правых взглядов [20, с. 22-31]. Свою задачу комиссия понимала как упорядочение всех положений о неприкосновенности личности, которые имелись на тот момент в действовавшем законодательстве.

Работы предшествовавших комиссий были полностью проигнорированы. Основные начала, имевшиеся в проекте III Государственной Думы, нивелировались формулировками типа «в порядке законом определённом» и сохранением в неприкосновенности тех обширных изъятий из закона, которые позволяли административной власти игнорировать права и свободы личности.

К решению проблемы неприкосновенности личности вернулись в IV Государственной Думе, в которую 3 декабря 1912 г. фракция кадетов вновь внесла законопроект «О неприкосновенности личности». Однако и в этом случае его легитимация не произошла.

Тем не менее, идеи конституционных демократов, содержавшиеся в законопроекте, внесённом в I Государственную Думу (проект 15-ти) и сохранённые в правительственном проекте, над которым работала II Государственная Дума (проект 33-х), отчасти получили легальное закрепление, но не в законе, а во Временном положении о милиции [5] (III период). В этом нормативном правовом акте с учётом теоретических разработок, имевшихся на тот момент, достаточно подробно регламентировалась процедура задержания, подвергшаяся принципиальным изменениям в сравнении с Уставом уголовного судопроизводства. Отметим, что подобной регламентации не имеет современное российское уголовно-процессуальное законодательство, в котором вопрос судебного контроля за ограничением неприкосновенности личности при применении задержания до настоящего времени открыт.

Чины милиции наделялись правом производить задержание только «бесчувственно пьяных», душевнобольных и «других, пребывание коих на свободе сопряжено с непосредственной опасностью для них самих или для окружающих» (ст. 25).

Обязательными условиями законности произведённого задержания являлись: составление протокола с указанием основания применения данной меры и немедленная выдача копии протокола по требованию задержанного либо ему самому, либо членам его семьи, либо его доверенному (ст. 26).

С требованием о предоставлении копии протокола могли обратиться лица, участвовавшие в деле, или члены семьи задержанного.

По их требованию чины милиции должны были предоставить протокол в течение 3-х дней (ст. 27).

Лица, задержанные без судебного решения («без письменного постановления о том судебной власти»), подлежали немедленному или в течение 24-х часов доставлению к судье или судебному следователю в соответствии с подведомственностью, 
если задержание произведено «в месте их пребывания». В остальных случаях к ближайшему судье или следователю (ст. 28).

В тех случаях, когда задержание состоялось в месте, отдалённом от места постоянного нахождения представителей судебной власти, двадцати четырёх часовой срок доставления увеличивался, «насколько это по местным условиям представляется необходимым» (ст. 29).

Действия начальника милиции и прочих чинов милиции могли обжаловаться в административном и судебном порядке. Действия начальника милиции в уездную или городскую управу, правительственному комиссару, прокурору или в административный суд; действия чинов милиции непосредственному начальнику, уездному комиссару, прокурору или в административный суд (ст. 45, 46). Можно было обжаловать не только задержание, но и иные действия.

Как видно из изложенного, в акте чётко фиксировался исчерпывающий перечень оснований задержания. Вводился повсеместный обязательный судебный контроль за произведённым задержанием с установлением жёстких сроков его реализации и последствий несоблюдения требований закона. Не только констатировалось право на обжалование произведённого задержания, но и обеспечивалась его реализация путём возложения на правоприменителя обязанности составлять протокол по каждому случаю задержания, выдавать его не только по требованию задержанного, но и по требованию членов его семьи и других участников уголовного дела в течение установленного срока. Несомненно, возможность выдачи протокола не только задержанному, но и его родственникам и другим участникам уголовного дела, да ещё в установленные сроки, является дополнительной гарантией прав задержанного, поскольку факт вручения протокола только задержанному затруднял бы реализацию права на обжалование произведённого задержания.

Закреплённая во Временном положении о милиции модель института задержания, как указывалось выше, легализовала идеи законопроекта «в обеспечение действительной неприкосновенности личности», внесённого по инициативе кадетов ещё в I Государственную Думу. Это была, безусловно, прогрессивная модель, закреплявшая гарантии неприкосновенности личности, подобные Habeas Corpus.

Таким образом, решение проблемы неприкосновенности личности, несмотря на теоретические предпосылки и практическую надобность, в России имело место только непродолжительное время в межреволюционный период (февраль - октябрь 1917 г.).

Такой результат деятельности Государственной Думы всех четырёх созывов по разрешению этого вопроса объясним несколькими причинами, в том числе скоротечностью деятельности I и II Государственной Думы (соответственно 27.04. - 08.07.1906 - 72 дня и 20.02. - 02.06.1907 - 102 дня); отсутствием традиций законодательной деятельности; неразработанностью теоретических понятий «указ» и «закон», что влияло на содержательную часть деятельности парламента, который был завален по образному выражению председателя II Государственной Думы Ф.А. Головина «законодательной вермишелью»; партийной пестротой состава парламента, внутрифракционной «грызней» и отсутствием фракционной дисциплины, 
влиявшими в совокупности на эффективность работы и принятие важных для России законов; несоответствием некоторой части депутатов возложенной на них миссии не только с точки зрения их характеристик (например, около $8 \%$ депутатов I Государственной Думы были судимы, $45 \%$ не имели высшего и среднего образования), но и с точки зрения отношения к делу (большинство во время выступления ораторов разговаривали, читали газеты, не посещали заседаний и т.п.; из 51 члена фракции кадетов в III Государственной Думе за первый год работы (до февраля 1909 г.) активно участвовали в дискуссиях только 11 человек); бесплановостью законодательной работы; использованием думской трибуны для самолюбования, упражнений в элоквенции [10, с. $36,38-40,42,43,103]$ и пр.

Неэффективность работы представительного органа подтверждается количественными показателями: в I Государственную Думу исполнительные органы внесли 16 законопроектов; во II - 287, в III - 2567, в IV - 2625 против внесенных депутатами соответственно 16 - 44 - 207 - 217 законопроектов [10, с. 35].

Как видим, идея неприкосновенности личности в дореволюционной России, несмотря на остроту и значимость этой проблемы, так и не была переведена в плоскость практической реализации. Составляющий в этом смысле исключение межреволюционный (февраль - октябрь 1917 г.) период был слишком недолгим, чтобы сформировать у практических работников традицию неукоснительного соблюдения прав и свобод личности.

1. Верещагина А.В. К вопросу о самостоятельности судебной власти и ее реализации в дореволюционном законодательстве // Российская юстиция. 2006. № 2. С. 44-46.

2. Верещагина А.В. Нужна ли реформа предварительного следствия? // Известия высших учебных заведений. Правоведение. 2005. № 1. С. 160-168.

3. Верещагина А.В. Обеспечение права обвиняемого на защиту на досудебных стадиях (по российскому дореволюционному законодательству) // Государство и право. 2002. № 5. С. 79-81.

4. Верещагина А.В. Становление и развитие уголовной юстиции России: дореволюционный период: монография. Владивосток: Изд-во ВГУЭС, 2009. 250 с.

5. Временное положение о милиции от 17. 04. 1917 // Вестник права. Орган адвокатуры, нотариата и суда. 1917. № 21. Ст. 537.

6. рацианский П.С. Политическая и правовая идеология России второй половины XVIII в. / отв. ред.: О.В. Мартышин. М.: Наука, 1984. 253 с.

7. Декларация и ответная речь П.А. Столыпина в Государственной думе 6 марта 1907 г. // Председатель Совета министров Пётр Аркадьевич Столыпин / сост. Е.В. по сообщениям прессы за три года (8 июля 1906 - 8 июля 1909 г.). СПб., 1909. С. 26-45.

8. Десницкий С.Е. Представление о учреждении законодательной, судительной и наказательной власти в Российской Империи // Избранные произведения русских мыслителей второй половины XVIII века. Т. І. М.: Госполитиздат, 1952. С. 292-332.

9. Записки С.Ю. Витте и его помощников Н.И. Вуича и кн. А.Д. Оболенского об обстоятельствах, при которых вырабатывался и был принят манифест. Докладные записки С.Ю. Витте Николаю II о необходимости выбирать между диктатурой и конституцией. Проекты манифеста, предложенные С.Ю. Витте и И.Л. Горемыкиным, и различные 
замечания к ним. Интервью С.Ю. Витте редакторам петербургских газет и журналов после издания манифеста // Красный архив. 1925. № 4-5. С. 39-106.

10. Соловьев К.А., Шелохаев В.В. История деятельности первых Государственных дум дореволюционной России: сравнительный анализ традиций правотворчества. М.: Издание Государственной Думы, 2013. 240 с.

11. Кистяковский Б.А. Очерки по методологии социальных наук и общей теории права. M., 1916. 708 c.

12. Леонтович В.В. История либерализма в России. 1762-1914 / под общ. ред. А.И. Солженицына. Париж: Умка-пресс, 1980. 549 с.

13. Люблинский П.И. Суд и права личности // Суд и права личности: сб. статей / под ред. Н.В. Давыдова, Н.Н. Полянского. М.: Статут; РАП, 2005. С. 32-70.

14. О предначертаниях к усовершенствованию государственного порядка: Именной Высочайший Указ, данный Сенату от 12 декабря 1904 года // ПСЗ. Собрание третье. T. XXIV. Отделение 1. №25495. СПб.: Государственная Типография, 1907.

15. Овчинников В.А., Николаева О.А. Юристы Первой Государственной Думы // Научнопрактический журнал Северо-Западной Академии государственной службы. 2006. № 1. С. 5-16.

16. Первая Государственная Дума: сб. статей. Выпуск второй, Законодательная работа. СПб.: Издание А.А. Муханова и В.Д. Набокова, 1907. 231 с.

17. Полный сборник платформ всех русских политических партий. СПб., 1906. 130 с.

18. Посошков И.Т. Книга о скудости и богатстве. М.: Изд-во АН СССР, 1951. 411 с.

19. Государственная Дума. Стенографические отчеты: 1906 год. Сессия первая: в 2 т. Т. 1: Государственная Дума. Стенографические отчеты: Заседания 1-18 (с 27 апреля по 30 мая) / Председатель Государственной Думы. Государственная типография. СПб.: Государственная типография, 1906. $866 \mathrm{c}$.

20. Хасин В.В. Саратовское дело Г.Г. Замысловского через призму общественных отношений XX века. Право и нравы // Известия Саратовского университета. 2012. Т. 12. Сер.: История. Международные отношения. Вып. 1. С. 22-31.

\section{Транслитерация}

1. Vereshchagina A.V. K voprosu o samostoyatel'nosti sudebnoi vlasti i ee realizatsii v dorevolyutsionnom zakonodatel'stve, Rossiiskaya yustitsiya, 2006, No 2, pp. 44-46.

2. Vereshchagina A.V. Nuzhna li reforma predvaritel'nogo sledstviya? Izvestiya vysshikh uchebnykh zavedenii. Pravovedenie, 2005, No 1, pp. 160-168.

3. Vereshchagina A.V. Obespechenie prava obvinyaemogo na zashchitu na dosudebnykh stadiyakh (po rossiiskomu dorevolyutsionnomu zakonodatel'stvu), Gosudarstvo i pravo, 2002, No 5, pp. 79-81.

4. Vereshchagina A.V. Stanovlenie i razvitie ugolovnoi yustitsii Rossii: dorevolyutsionnyi period: monografiya. Vladivostok: Izd-vo VGUES, 2009. $250 \mathrm{~s}$.

5. Vremennoe polozhenie o militsii ot 17.04.1917, Vestnik prava. Organ advokatury, notariata i suda, 1917, No 21, st. 537.

6. Gratsianskii P.S. Politicheskaya i pravovaya ideologiya Rossii vtoroi poloviny XVIII v. / otv. red.: Martyshin O. V. M.: Nauka, 1984. 253 c.

7. Deklaratsiya i otvetnaya rech' P.A. Stolypina v Gosudarstvennoi dume 6 marta $1907 \mathrm{~g}$. Predsedatel' Soveta ministrov Petr Arkad'evich Stolypin. Sostavleno E.V. Po soobshcheniyam pressy za tri goda (8 iyulya $1906-8$ iyulya 1909 g. Izdanie sostavitelya. SPb., 1909. pp. $26-45$. 
8. Desnitskii S.E. Predstavlenie o uchrezhdenii zakonodatel'noi, suditel'noi i nakazatel'noi vlasti v Rossiiskoi Imperii, Izbrannye proizvedeniya russkikh myslitelei vtoroi poloviny XVIII veka, vol. I. M.: Gospolitizdat, 1952. pp. 292-332.

9. Zapiski S.Yu. Vitte i ego pomoshchnikov N.I. Vuicha i kn. A.D. Obolenskogo ob obstoyatel'stvakh, pri kotorykh vyrabatyvalsya i byl prinyat manifest. Dokladnye zapiski S.Yu. Vitte Nikolayu II o neobkhodimosti vybirat' mezhdu diktaturoi i konstitutsiei. Proekty manifesta, predlozhennye S.Yu. Vitte i I.L. Goremykinym, i razlichnye zamechaniya k nim. Interv'yu S.Yu. Vitte redaktoram peterburgskikh gazet i zhurnalov posle izdaniya manifesta, Krasnyi arkhiv, 1925, No 4-5, pp. 39-106.

10. Solov'ev K.A., Shelokhaev V.V. Istoriya deyatel'nosti pervykh Gosudarstvennykh dum dorevolyutsionnoi Rossii: sravnitel'nyi analiz traditsii pravotvorchestva. M.: Izdanie Gosudarstvennoi Dumy, 2013. 240 p.

11. Kistyakovskii B.A. Ocherki po metodologii sotsial'nykh nauk i obshchei teorii prava. M., 1916. 708 p.

12. Leontovich V.V. Istoriya liberalizma v Rossii. 1762-1914 / pod obshch. red. A. I. Solzhenitsyna. Parizh: Umka-press, 1980. 549 p.

13. Lyublinskii P.I. Sud i prava lichnosti, Sud i prava lichnosti: sbornik statei, pod red. N.V. Davydova, N.N. Polyanskogo. M.: Statut; RAP, 2005. S. 32-70.

14. O prednachertaniyakh $\mathrm{k}$ usovershenstvovaniyu gosudarstvennogo poryadka: Imennoi Vysochaishii Ukaz, dannyi Senatu ot 12 dekabrya 1904 goda, PSZ. Sobranie tret'e, vol. XXIV, otd. 1, No 25495. SPb.: Gosudarstvennaya Tipografiya, 1907.

15. Ovchinnikov V.A., Nikolaeva O.A. Yuristy Pervoi Gosudarstvennoi Dumy, Nauchnoprakticheskii zhurnal Severo-Zapadnoi Akademii gosudarstvennoi sluzhby, 2006, No 1, pp. 5-16.

16. Pervaya Gosudarstvennaya Duma: Sbornik statei. Vypusk vtoroi, Zakonodatel'naya rabota. S.-Peterburg: Izdanie A.A. Mukhanova i V.D. Nabokova,1907. 231 p.

17. Polnyi sbornik platform vsekh russkikh politicheskikh partii. SPb., 1906. 130 p.

18. Pososhkov I.T. Kniga o skudosti i bogatstve. M.: Izd-vo AN SSSR, 1951. 411 p.

19. Gosudarstvennaya Duma. Stenograficheskie otchety [Tekst]: 1906 god. Sessiya pervaya. V 2-kh t. vol. 1. Gosudarstvennaya Duma. Stenograficheskie otchety: Zasedaniya 1-18 (s 27 aprelya po 30 maya) / Predsedatel' Gosudarstvennoi Dumy. - Gosudarstvennaya tipografiya. $\mathrm{SPb}$.: Gosudarstvennaya tipografiya, 1906. 866 p.

20. Khasin V.V. «Saratovskoe delo G. G. Zamyslovskogo cherez prizmu obshchestvennykh otnoshenii XX veka. Pravo i nravy, Izvestiya Saratovskogo universiteta, 2012, vol. 12, ser. Istoriya. Mezhdunarodnye otnosheniya, iss. 1, pp. 22-31.

\section{(C) А.В. Верещагина, 2018}

Для цитирования: Верещагина А.В. Идея неприкосновенности личности и опыт её реализации в досоветской России // Территория новых возможностей. Вестник Владивостокского государственного университета экономики и сервиса. 2018. Т. 10. №3. С. 62-71.

For citation: Vereshchagina A.V. Personal immunity idea and the experience of its realization in preSoviet Russia, The Territory of New Opportunities. The Herald of Vladivostok State University of Economics and Service, 2018, Vol. 10, No3, pp. 62-71.

DOI dx.doi.org/10.24866/VVSU/2073-3984/2018-3/062-071

Дата поступления: 27.07.2018. 